\title{
Prevention and Reversal of Adoptively Transferred, Chronic Relapsing Experimental Autoimmune Encephalomyelitis with a Single High Dose Cytoreductive Treatment Followed by Syngeneic Bone Marrow Transplantation
}

\author{
D. M. Karussis, ${ }^{\star}$ U. Vourka-Karussis, ${ }^{\ddagger}$ D. Lehmann, ${ }^{\star}$ H. Ovadia, ${ }^{\star}$ R. Mizrachi-Koll, ${ }^{\star}$ A. Ben-Nun, ${ }^{\star}$ O. Abramsky, ${ }^{\star}$ and S. Slavin \\ ${ }^{*}$ Department of Neurology and Neuroimmunology Research Unit and ${ }^{\ddagger}$ Department of Bone Marrow Transplantation and Cancer \\ Immunobiology Research Laboratory, Hadassah-Hebrew University Hospital, Jerusalem, Israel, IL-91120; and ${ }^{\S}$ Department of Cell \\ Biology, The Weizmann Institute of Science, Rehovot, Israel, IL-76000
}

\begin{abstract}
A chronic relapsing form of experimental autoimmune encephalomyelitis (CR-EAE) was induced in SJL/J mice by adoptive transfer of lymph node cells (LNC) sensitized to guinea pig myelin basic protein (GMBP). We examined the efficacy of high dose immunosuppressive regimens (cyclophosphamide [CY] $300 \mathrm{mg} / \mathrm{kg}$ or total body irradiation [TBI] $900 \mathrm{cGy}$ ) followed by syngeneic bone marrow transplantation (SBMT) in prevention and treatment of already established CR-EAE. Treatment with TBI and SBMT on day 5 after the induction of CR-EAE, just before the onset of clinical signs, completely inhibited the appearance of the paralytic signs. The same treatment, applied $4 \mathrm{~d}$ after the clinical onset of the disease, led to a significant regression of the paralytic signs and to a total inhibition of spontaneous relapses during a follow-up period of $2 \mathrm{mo}$. Challenge of mice with GMBP+CFA $78 \mathrm{~d}$ after the passive induction of CR-EAE induced a relapse of the disease $7 \mathrm{~d}$ later in almost all of the untreated mice; in contrast, the same challenge given to TBI+SBMT-treated mice caused a delayed relapse (30 d later) in only a minority (3/7) of the challenged mice. In vitro lymphocytic proliferative responses to GMBP and purified protein derivative were significantly lower in TBI+SBMT-treated mice before and after the GMBP challenge, although these mice were fully immunocompetent, as evidenced by their normal lymphocytic proliferation to concanavalin A (ConA) and the FACS ${ }^{\circledR}$ analysis of their lymphocytic subpopulations. A similar beneficial therapeutic effect was observed in mice treated with CY followed by SBMT, after the onset of CR-EAE. Our results could support possible clinical applications of similar therapeutic strategies, involving acute immunosuppression followed by stem cell transplantation and retolerization of the reconstituting immune cells in life-threatening neurological and multisystemic autoimmune diseases. $(J$. Clin. Invest. 1993. 92:765-772.) Key words: chronic relapsing experimental autoimmune encephalomyelitis - bone marrow transplantation • cyclophosphamide $\cdot$ total body irradiation • tolerance
\end{abstract}

Address reprint requests to D. M. Karussis, M.D., Department of Neurology, Hadassah University Hospital, Ein Karem, Jerusalem, Israel IL-91120.

Received for publication 4 April 1992 and in revised form 24 August 1992.

J. Clin. Invest.

(c) The American Society for Clinical Investigation, Inc. 0021-9738/93/08/0765/08 \$2.00

Volume 92, August 1993, 765-772

\section{Introduction}

The chronic relapsing form of experimental autoimmune encephalomyelitis (CR-EAE) ${ }^{1}$ in mice is characterized clinically by relapses and remissions of paralytic signs and pathologically by demyelinating lesions in the white matter of the central nervous system (1-5), resembling multiple sclerosis in humans (6). CR-EAE is induced in SJL/J mice by adoptive transfer of lymphocytes that have been sensitized in vitro to myelin basic protein (MBP) (3). T cells are crucial for the development of EAE and CR-EAE $(7,8)$. T cells of the Lyt-1 phenotype were observed in perivascular cuffs in the brain and spinal cord of animals with EAE (9), and T cell clones that react with the encephalitogenic determinant of basic protein were proved sufficient to induce the disease (10).

Treatment of the acute form of EAE was previously achieved using several immunosuppressive regimens (11-25). Cyclophosphamide $(\mathrm{CY})$ was shown to be a very effective agent for inhibition of actively and passively induced acute EAE (1622). However, treatment of CR-EAE requires chronic administration of the cytoreductive drug, and the cessation of treatment is often associated with reappearance of paralytic signs and a severe neurological outcome $(19,20,22)$. Moreover, the chronic treatment is accompanied with acumulative toxic side effects.

Treatment of an ongoing CR-EAE with apparent paralytic signs and histological damage was always a difficult task, especially in the form of CR-EAE passively induced with T cells that were presensitized with MBP and subsequently activated in vitro. Effective inhibition of CR-EAE was accomplished with administration of anti-CD4 (26-28) monoclonal antibodies, and recently through MBP feeding (29).

In this study, we tried a different approach to treat adoptively transferred CR-EAE in SJL/J mice: a single application of a high dose of CY or TBI for effective elimination of the autoreactive lymphocytes, followed by bone marrow transplantation obtained from healthy syngeneic donors, to rescue the immunocompromised mice and to provide them with a source of uncommitted lymphoid progenitors for reinduction of unresponsiveness toward "self." We evaluated the efficacy of this treatment in inhibition of further paralytic relapses and in the induction of antigen-specific tolerance during the process of immune reconstitution.

1. Abbreviations used in this paper: ConA, concanavalinA; CR-EAE, chronic relapsing experimental autoimmune encephalomyelitis; CY, cyclophosphamide; GMBP, guinea pig myelin basic protein; LNC, lymph node cells; MBP, myelin basic protein; PPD, purified protein derivative; SBMT, syngeneic bone marrow transplantation; TBI, total body irradiation. 


\section{Methods}

Mice: 6-12-wk-old female SJL/J mice were purchased from the Jackson Laboratory (Bar Harbor, ME) and housed under standard conditions in top-filtered cages. Mice were fed a regular diet and given acidified water without antibiotics.

Antigens: Spinal cords from 3-10-mo-old mice of various strains were obtained by insufflation. Mouse spinal cord homogenate was prepared by homogenization in PBS $(1: 1 \mathrm{vol} / \mathrm{vol})$. The homogenate was lyophilized, reconstituted in PBS to a concentration of $100 \mathrm{mg} / \mathrm{ml}$ (dry $\mathrm{wt}$ ), and stored at $-20^{\circ} \mathrm{C}$ until used. Tuberculin purified protein derivative (PPD) was obtained from Statens Seruminstitut, Copenhagen, Denmark. Guinea pig myelin basic protein (GMBP) was prepared from guinea pig spinal cords as previously described (30).

Passive induction and clinical evaluation of CR-EAE. Donors (SJL/ $\mathrm{J}$ mice) of sensitized T cells were immunized with guinea pig MBP (GMBP) in Freund's adjuvant. Mice were injected subcutaneously at two to three sites over the flanks with $400 \mathrm{mg}$ of GMBP and CFA containing $0.03 \mathrm{mg}$ of Mycobacterium tuberculosis. Animals were killed $10 \mathrm{~d}$ later under ether anesthesia, and draining (inguinal, axial, and paraaortic) lymph nodes were aseptically excised, teased in PBS, and passed through a wire mesh to obtain a single cell suspension of lymph node cells (LNC). The LNC were adjusted to $4 \times 10^{6}$ cells $/ \mathrm{ml}$ and cultured for $4 \mathrm{~d}$ in $37^{\circ} \mathrm{C}$ and $5 \% \mathrm{CO}_{2}$ into 24-well $(2 \mathrm{ml} /$ well) culture plates (Costar Corp., Cambridge, MA). RPMI- 1640 culture medium was used, containing $10 \% \mathrm{FCS}, 1 \%$ pyruvate, $1 \%$ nonessential amino acids, $1 \%$ L-glutamine, $1 \%$ mercaptoethanol, and $1 \%$ penicillin and streptomycin. GMBP was added in a concentration of 50-100 $\mu \mathrm{g} / \mathrm{ml}$. Cell suspensions were washed in fresh RPMI-1640 medium and adjusted to between 30 and $60 \times 10^{6}$ viable cells $/ 0.5 \mathrm{ml}$. This inoculum was injected intravenously into the tail vein of naive syngeneic $\mathrm{SJL} / \mathrm{J}$ recipients. The first clinical signs of CR-EAE usually appeared 7-16 d after cell transfer, and a chronic disease with relapses and remissions followed the first attack.

Clinical signs were scored as follows: 0 , no clinical signs; 1 , mild tail weakness (floppy tail); 2 , tail paralysis; 3 , hind leg paralysis; 4 , hind leg paralysis or mild forelimb weakness; 5 , quadriplegia or moribund state; 6 , death. Any deterioration of clinical signs of at least one degree on the above scale for more than three consecutive days (after a period of remission) was considered a relapse.

Histopathological evaluation. For routine histology, mice were killed using ether anesthesia and then perfused extensively with PBSbuffered formalin. Brains and spinal cords were removed and processed for paraffin embedding. Tissue sections were stained with hematoxylin-eosin and Luxol fast blue. Histological evaluation was done on a blind basis by an independent pathologist.

Administration of CY. CY (Taro, Haifa, Israel) was freshly dissolved in sterile water and administered intravenously as a single dose of $300 \mathrm{mg} / \mathrm{kg}$ body wt.

Total body irradiation (TBI). Mice were positioned in radiation chambers and exposed to a single dose of $900-1100$ cGy TBI from a gamma beam $150-\mathrm{A}{ }^{60} \mathrm{Co}$ source (produced by the Atomic Energy of Canada, Kanata, Ontario). Skin-to-source distance was $105 \mathrm{~cm}$ and the dose rate was $65 \mathrm{cGy} / \mathrm{min}$.

Syngeneic bone marrow transplantation (SBMT). Bone marrow cells were obtained from $\mathrm{SJL} / \mathrm{J}$ mice by flushing femora and humora with RPMI- 1640 medium. Viability of cells was determined by trypan blue exclusion. 10-20 $\times 10^{6}$ cells were injected intravenously into the lateral tail vein of syngeneic recipients, $24 \mathrm{~h}$ after TBI or CY.

In vitro proliferative responses of lymphocytes. Single cell suspensions of lymph node lymphocytes were assayed in vitro for their response to antigens by means of a standard proliferative assay. The assay was carried out by seeding in each microculture well $4 \times 10^{5}$ cells in 0.2 $\mathrm{ml}$ of RPMI medium supplemented with $2.5 \%$ FCS, 1-glutamine, 2 mercaptoethanol antibiotics, and optimal concentrations of the following antigens: $50 \mu \mathrm{g} / \mathrm{ml}$ of GMBP, $50 \mu \mathrm{g} / \mathrm{ml}$ of PPD, and $1 \mu \mathrm{g} / \mathrm{ml}$ of concanavalin A (ConA). All cultures were performed in triplicate in 96-well, flat-bottom, microtiter plates (Costar Corp.), incubated for
$72 \mathrm{~h}$ in a humidified atmosphere of $5 \% \mathrm{CO}_{2}$ in air at $37^{\circ} \mathrm{C}$, and then pulsed for $18 \mathrm{~h}$ with $1.0 \mu \mathrm{Ci}$ of $\left[{ }^{3} \mathrm{H}\right]$ thymidine (New England Nuclear, Boston, MA). Cells from each microculture were harvested on fiberglass filters using a multiharvester (Dynatech Laboratories, Alexandria, VA), and the incorporated radioactivity was measured using standard scintillation techniques. The stimulation index (SI) was calculated as follows: mean cpm of cells cultured in the presence of antigen divided by the mean cpm of cells cultured in the absence of antigen.

Analysis of T lymphocyte populations. Surface markers of lymphocytes from pooled spleen cells obtained from naive mice, untreated mice with CR-EAE, and mice with CR-EAE treated with TBI+SBMT were analyzed. $50 \mu \mathrm{l}$ of cell suspension $\left(2 \times 10^{7}\right.$ cells $\left./ \mathrm{ml}\right)$ was mixed with $5 \mu$ l FITC-conjugated monoclonal anti-CD3, anti-L3T4, or phycoerythrin-conjugated anti-Lyt-2 and anti-IgM antibodies (BectonDickinson, Mountain View, CA) and $45 \mu \mathrm{l}$ PBS containing $0.1 \%$ sodium azide and $2 \%$ FCS. The cell mixture was incubated for $45 \mathrm{~min}$ on ice, washed twice, and resuspended in $1 \mathrm{ml}$ of cold medium $\left(10^{6} / \mathrm{ml}\right)$. Positively stained cells were enumerated by a fluorescence-activated cell sorter (FACS ${ }^{\oplus}$, Becton-Dickinson).

\section{Results}

Effect of acute cytoreductive treatment (TBI or CY) followed by $S B M T$ on the clinical course of CR-EAE. SJL/J mice were treated $5 \mathrm{~d}$ after the injection of GMBP-stimulated LNC ( $2 \mathrm{~d}$ before the expected onset of paralysis) with TBI (900 cGy), followed $1 \mathrm{~d}$ later by SBMT. As shown in Fig. 1, no clinical signs of CR-EAE appeared in TBI+SBMT-treated mice during an observation period of $>70 \mathrm{~d}$. In contrast, all the control animals (8/8) developed a relapsing-remitting disease with severe paralytic signs (mean clinical score: 3.2 ) (Fig. 1, $P$ $<0.0001$ ).

Cytoreductive treatment with CY $(300 \mathrm{mg} / \mathrm{kg})$ followed by SBMT at an early stage of clinical CR-EAE (immediately after the first clinical signs of paralysis) inhibited the development of the disease $(P<0.001)$ (Fig. 2); untreated control mice $(6 / 7)$ progressed to severe paralysis, followed by a relapsing-remitting course. Table I $A$ shows the 2-mo follow-up in both groups; a total number of seven relapses were observed in the untreated

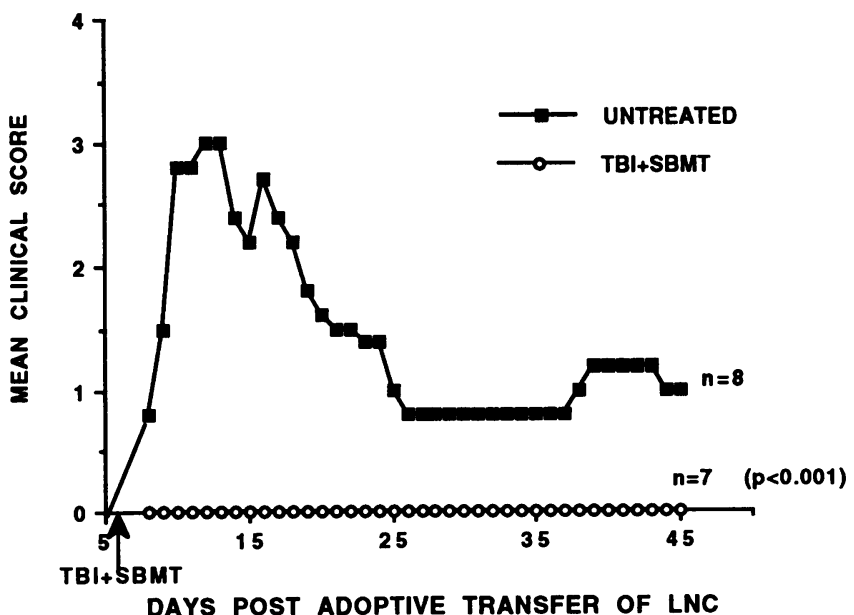

Figure 1. Prevention of passively induced CR-EAE in SJL/J mice with TBI followed by SBMT. Mice were injected on day 0 with 50 $\times 10^{6} \mathrm{GMBP}$-sensitized LNC as described in Methods. On day 5 after the adoptive transfer of $\mathrm{LNC}$, mice were either left untreated or were treated with TBI followed by SBMT (as described in Methods). Mice were examined daily for signs of EAE and scored according to a 0-6 scale of increasing severity of the disease. 


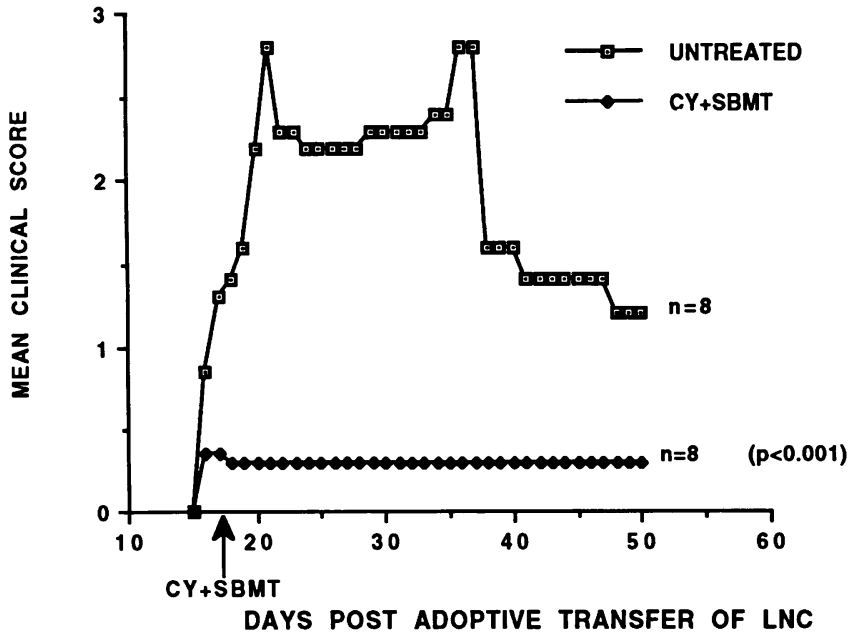

Figure 2. Therapeutic effect of CY+SBMT performed immediately after the clinical onset of CR-EAE. SJL/J mice were injected on day 0 with $50 \times 10^{6} \mathrm{GMBP}$-sensitized LNC. One day after the onset of the first paralytic signs, mice were divided in groups ( 8 mice/group) with a similar mean clinical score and were treated with either CY followed by SBMT (as described in Methods) or left untreated. Mice were examined daily for signs of EAE and scored according to a 0-6 scale of increasing severity of the disease.

group during this period, whereas no relapses were noted in the CY+SBMT-treated group $(P<0.03)$.

The efficacy of the above treatment was evaluated in mice that had already developed paralytic signs. Mice were treated 3-4 d after the onset of paralysis with either high dose CY or TBI, followed by SBMT. The clinical course of CR-EAE in untreated and in TBI+SBMT- or CY+SBMT-treated mice is presented in Fig. 3 and 4, respectively. A significant regression of the clinical signs (Fig. 3, 4) occurred after both cytoreductive regimens regimens $(P<0.001$ and $P<0.0001$, respectively). Both of these therapeutic interventions also inhibited the appearance of further paralytic relapses. As shown in Table I $B$, a total of 11 relapses was observed in the seven untreated mice during a period of $2 \mathrm{mo}$, whereas no relapses occurred in the TBI+SBMT-treated group $(P<0.02)$. In another experiment (where mice received CY instead of TBI), a total of 19 relapses was observed in the untreated group during a period of 4 mo (Table I C); only 5 relapses occurred in mice treated with CY followed by SBMT $(P<0.03)$ and the severity of the relapses was milder (mean maximal score:3.1 in untreated and 1.9 in the CY+SBMT-treated mice, $P<0.03$ ) (Table I $C$ ). The longlasting effect of SBMT treatment was evaluated by challenging the treated mice with a subcutaneous injection of GMBP in CFA $72 \mathrm{~d}$ after the transfer of the GMBP-sensitized lymphocytes. This immunologic challenge induced a severe paralytic relapse in six of seven $(86 \%)$ untreated control mice $7 \mathrm{~d}$ later (Fig. 3); only three of the seven TBI+SBMT-treated mice developed paralytic signs with a delay of $30 \mathrm{~d}$, after the GMBP injection (Table I $B$, Fig. 3). Similar results were obtained in mice treated with $\mathrm{CY}+\mathrm{SBMT}$ and rechallenged with GMBP (data not shown).

Treatment with TBI or CY followed by SBMT at a later stage of the disease ( $14 \mathrm{~d}$ after the first paralytic signs and at a point where all mice were severely paralyzed) produced a mild therapeutic effect on the course of the disease $(P<0.01)$ (Fig. 5) (data shown only for TBI+SBMT), but did not significantly inhibit the occurrence of further paralytic relapses (data not shown).

In vitro proliferative responses of $L N C$ to $G M B P$ and $P P D$. LNC obtained ( $60 \mathrm{~d}$ after the SBMT) from control mice suffering from CR-EAE displayed a clear proliferative response to GMBP and PPD $78 \mathrm{~d}$ after the adoptive transfer of GMBP-sensitized LNC (Table II $A$ ). In contrast, LNC from mice similarly injected with GMBP-specific lymphocytes and treated with TBI+SBMT showed a weaker response to the same antigens (GMBP and PPD) $(P<0.01)$ (Table II $A$ ).

Immunologic challenge of the untreated mice with GMBP enhanced the proliferative response to GMBP and PPD (examined $10 \mathrm{~d}$ later) (Table II $B$ ). The in vitro reactivity of lymphocytes from mice with CR-EAE treated with TBI+SBMT and similarly challenged with GMBP remained lower $(P<0.01)$ (Table II $B$ ). This finding may be attributed to either active suppression of the autoimmune clones or generalized immunological anergy after SBMT, since the ConA-induced proliferation was also reduced. Similar results were obtained in mice treated with CY+SBMT (data not shown).

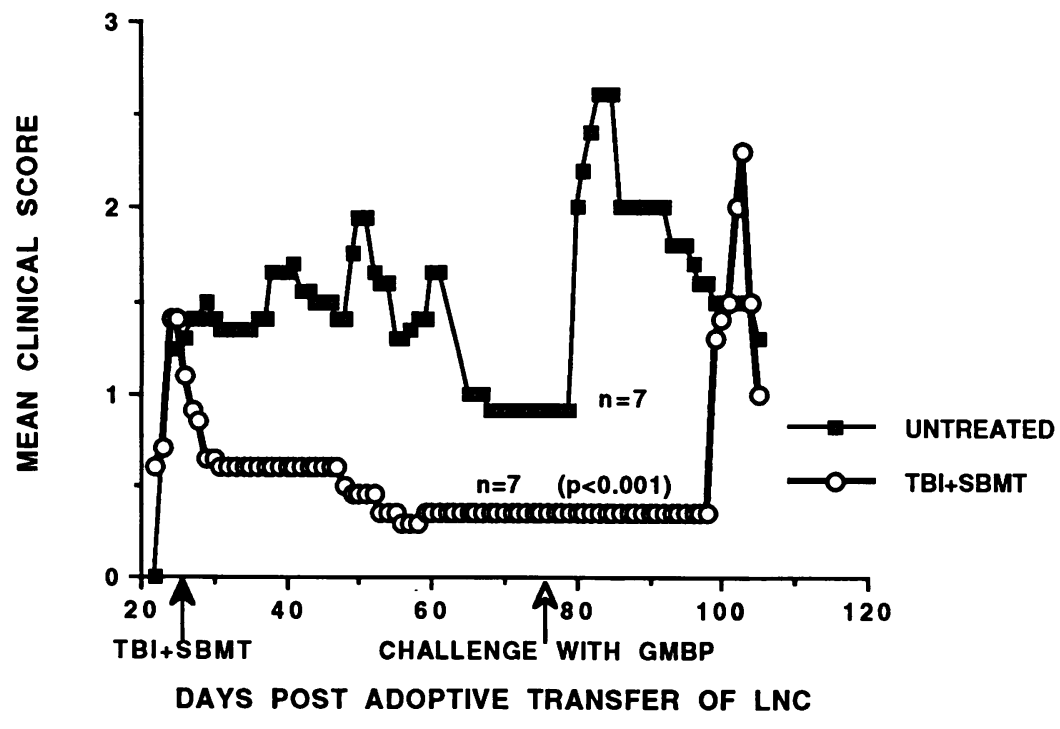

Figure 3. Therapeutic effect of TBI+SBMT performed $3 \mathrm{~d}$ after the clinical onset of CR-EAE. SJL/J mice were injected on day 0 with $50 \times 10^{6} \mathrm{GMBP}-$ sensitized LNC. $3 \mathrm{~d}$ after the onset of the first paralytic signs, mice were divided in groups $(7 \mathrm{mice} /$ group) with a similar mean clinical score (1.5) and were either left untreated or treated with TBI followed by SBMT (as described in Methods). Mice were examined daily for signs of EAE and scored according to a 0-6 scale of increasing severity of the disease. On day 72 after the adoptive transfer of LNC, all mice were challenged with GMBP in adjuvant, injected subcutaneously. 


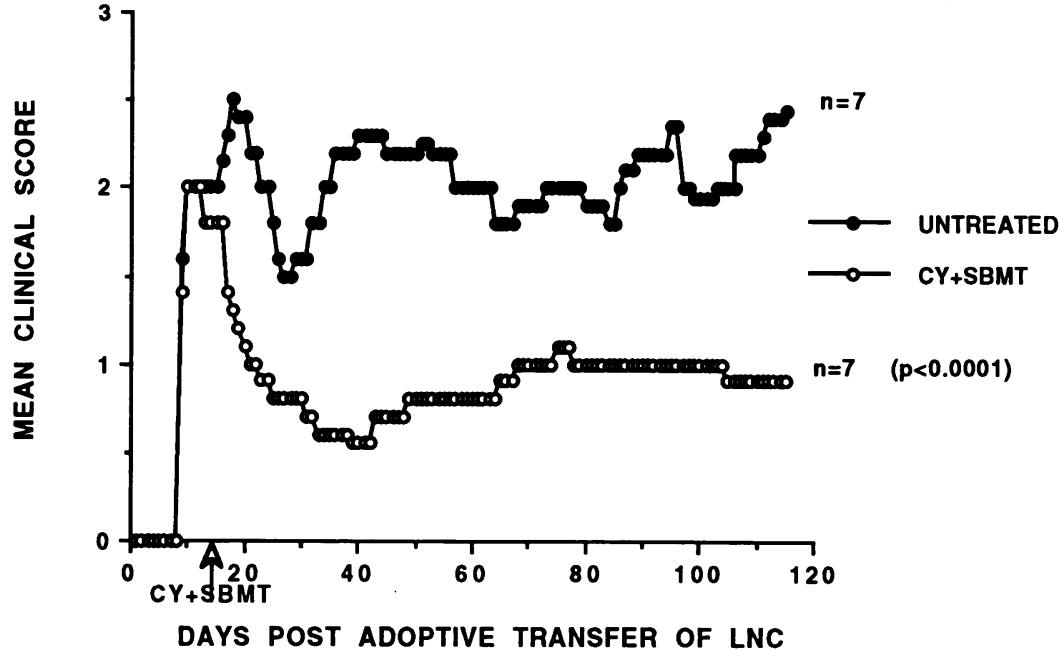

Figure 4. Therapeutic effect of CY+SBMT performed $4 \mathrm{~d}$ after the clinical onset of CR-EAE. SJL/J mice were injected on day 0 with $50 \times 10^{6} \mathrm{GMBP}$-sensitized LNC. $4 \mathrm{~d}$ after the onset of the first paralytic signs, mice were divided in groups ( 7 mice/group) with a similar mean clinical score (2.0) and were either left untreated or treated with $\mathrm{CY}$ followed by SBMT (as described in Methods). Mice were examined daily for signs of EAE and scored according to a 0-6 scale of increasing severity of the disease.
Analysis of lymphocyte subpopulations. Spleen cells obtained from untreated and TBI+SBMT-treated mice with CREAE were examined by FACS $^{\circledR}$ analysis for the expression of CD3, L3T4, Lyt-2, and IgM surface markers, $78 \mathrm{~d}$ after the induction of CR-EAE. Table III shows the proportions of the lymphocyte subpopulations in the spleens of both experimental groups. It can be seen that at day 60 after TBI+SBMT all mice were fully reconstituted with mature immune cells with no significant differences in the proportions of lymphocyte subsets including $\mathrm{T}$ helpers (L3T4), T-cytotoxic/suppressors (Lyt-2), and B cells (IgM) between the two groups (Table III).

Histopathological evaluation. Mice were killed at various time intervals after the injection of the GMBP-sensitized LNC, and brain and spinal cord sections from untreated CR-EAE control mice and from mice treated with CY or TBI and SBMT were observed for histopathological signs of CR-EAE. In sections from untreated mice, perivascular infiltrations of mononuclear cells into the periventricular and cerebellar white mat-

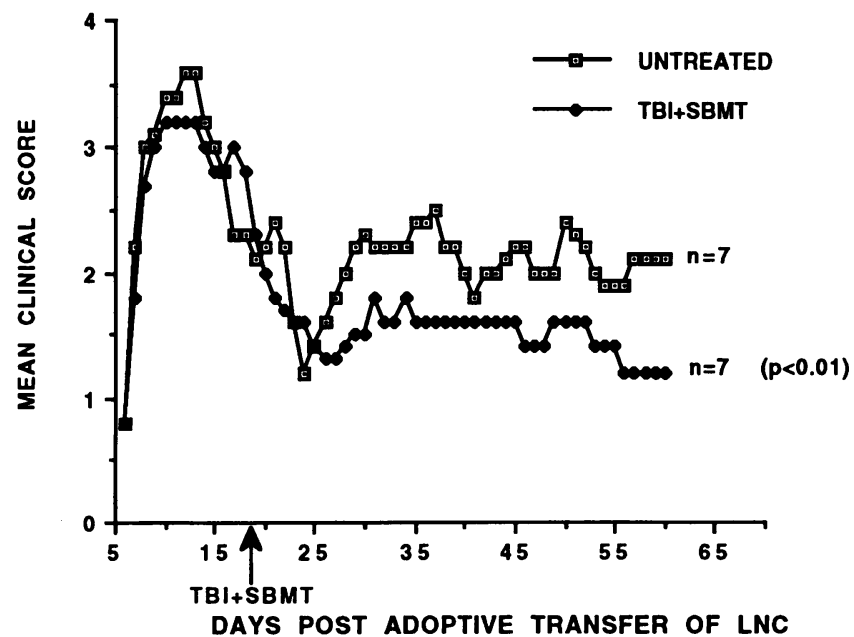

Figure 5. Effect of treatment with TBI+SBMT performed at a late stage after the clinical onset of CR-EAE. SJL/J mice were injected on day 0 with $50 \times 10^{6}$ GMBP-sensitized LNC. $14 \mathrm{~d}$ after the onset of the first paralytic signs, mice were divided in groups ( 7 mice/group) with a similar mean clinical score (2.0) and were either left untreated or treated with TBI followed by SBMT (as described in Methods).

Mice were examined daily for signs of EAE and scored according to a 0-6 scale of increasing severity of the disease. ter were seen (Fig. 6A). Luxol fast blue staining revealed large areas of demyelination around the infiltrations (Fig. $6 \mathrm{~A}$ ). In brain sections from mice treated with TBI and SBMT, the number and the severity of lesions were significantly reduced (Fig. $6, B$ and $C$ ). Similar amelioration of the central nervous system

Table I. Incidence and Severity of Relapses in Mice with CR-EAE Treated with $C Y+S B M T$ or $T B I+S B M T$ in Comparison to Untreated CR-EAE Controls

A

Untreated $\quad$ CY + SBMT

Cumulative number of spontaneous relapses in a period of $2 \mathrm{mo}$

Mean maximal clinical score during relapses

$3.3 \pm 0.3$

$0(P<0.03)^{*}$

\begin{tabular}{|c|c|c|}
\hline during relapses & $3.3 \pm 0.3$ & $0(P<0.02)^{*}$ \\
\hline B & Untreated & $\mathrm{TBI}+\mathrm{SBMT}$ \\
\hline $\begin{array}{l}\text { Cumulative number of } \\
\text { spontaneous relapses } \\
\text { in a period of } 2 \text { mo } \\
\text { Incidence of an induced } \\
\text { relapse after rechallenge } \\
\text { with GMBP }\end{array}$ & $6 / 7(86 \%)$ & $0(P<0.03)^{*}$ \\
\hline $\mathrm{C}$ & Untreated & $\mathrm{CY}+\mathrm{SBMT}$ \\
\hline $\begin{array}{l}\text { Cumulative number of } \\
\text { spontaneous relapses } \\
\text { in a period of } 2 \text { mo }\end{array}$ & 19 & $6(P<0.03)^{*}$ \\
\hline $\begin{array}{l}\text { Mean maximal clinical score } \\
\text { during relapses }\end{array}$ & $3.1 \pm 0.2$ & $1.9 \pm 0.35(P<0.03)^{*}$ \\
\hline
\end{tabular}

All mice were injected on day 0 with $50 \times 10^{6} \mathrm{GMBP}$-sensitized LNC. 1-4 $\mathrm{d}$ after the onset of the first paralytic signs, mice were divided in groups (8 mice/group) with a similar mean clinical score and were treated with either CY or TBI followed by SBMT (as described in Methods) or left untreated. Mice were examined daily for signs of EAE and scored according to a 0-6 scale of increasing severity of the disease. Relapse was considered any clinical deterioration of at least 1 degree for more than $3 \mathrm{~d}$. * nonparametric Mann Whitney test. 
Table II. Proliferative Responses of Lymph Node Cells from Untreated and TBI + SBMT-treated Mice

\begin{tabular}{lcc}
\hline \multicolumn{1}{c}{ Antigens } & Untreated & TBI + SBMT \\
\hline A. 60 d following SBMT & & \\
PPD & $2869 \pm 166$ & $1393 \pm 316(P<0.01)^{*}$ \\
GMBP & $5498 \pm 634$ & $3229 \pm 398(P<0.01)^{*}$ \\
CON-A & $94014 \pm 7803$ & $71026 \pm 7539$ \\
B. $10 \mathrm{~d}$ following & & \\
rechallenge with & & \\
GMBP & & \\
PPD & $14956 \pm 1776$ & $9071 \pm 1088(P<0.01)^{*}$ \\
GMBP & $41467 \pm 4356$ & $17089 \pm 428(P<0.01)^{*}$ \\
CON-A & $51027 \pm 9188$ & $31548 \pm 3329(P<0.05)^{*}$ \\
\end{tabular}

All mice were injected with $50 \times 10^{6} \mathrm{GMBP}$-sensitized lymphocytes for induction of CR-EAE, on day 0 , as described in Methods. $4 \mathrm{~d}$ after the clinical onset of CR-EAE, one group of mice was treated with TBI ( $900 \mathrm{cGy}$ ) followed by SBMT. Pooled LNC ( 3 mice) from both (treated and untreated) groups were obtained on day 60 after the SBMT and again on day 10 following a rechallenge with GMBP and were examined for their in vitro proliferative responses to PPD, GMBP, and ConA. One representative of two experiments is shown. Results presented as Dcpm; background $\leq 5000 \mathrm{cpm}$. * one factor ANOVA analysis (Fischer PLSD and Scheffe F test).

(CNS) pathology was observed in mice treated with CY followed by SBMT (data not shown).

\section{Discussion}

In this study, which represents an extension of our initial observation on the beneficial role of acute cytoreductive treatment combined with SBMT on acute EAE (31), we have documented that high dose CY or TBI followed by SBMT can inhibit and even reverse already clinically established CR-EAE, induced by adoptive transfer of MBP-sensitized lymphocytes in SJL/J mice. This treatment also prevented the appearance of paralytic relapses and induced immunological unresponsiveness to the relevant immunizing antigens GMBP and PPD.

Table III. Analysis of the Cell Surface Phenotype of Spleen Cells Obtained from Mice with CR-EAE Treated with TBI + SBMT and from Untreated Controls

\begin{tabular}{llcr}
\hline $\begin{array}{l}\text { Surface } \\
\text { markers }\end{array}$ & $\begin{array}{c}\text { Naive SJL } \\
\text { mice }\end{array}$ & $\begin{array}{c}\text { Untreated } \\
\text { CR-EAE }\end{array}$ & $\begin{array}{c}\text { TBI + SBMT } \\
\text { treated }\end{array}$ \\
\hline CD3 & $66.4 \%$ & $67.3 \%$ & $65.4 \%$ \\
L3T4 & $46 \%$ & $35.2 \%$ & $32.9 \%$ \\
Lyt-2 & $12.6 \%$ & $7.5 \%$ & $8.3 \%$ \\
IgM & $33.5 \%$ & $33.1 \%$ & $37.4 \%$ \\
\hline
\end{tabular}

$\mathrm{SJL} / \mathrm{J}$ mice were injected with $50 \times 10^{6} \mathrm{GMBP}$-sensitized lymphocytes for induction of CR-EAE, on day 0 , as described in Methods. $4 \mathrm{~d}$ after the clinical onset of CR-EAE, one group of mice was treated with TBI ( $900 \mathrm{cGy}$ ) followed by SBMT. Pooled spleen cells ( 3 mice) from untreated mice, mice treated with TBI + SBMT, and from naive $\mathrm{SJL} / \mathrm{J}$ mice of the same age were obtained on day 60 after the SBMT and the various lymphocytic subpopulations were examined by FACS $^{\otimes}$ analysis of their CD3, L3T4, Lyt-2, and IgM surface markers.
The suppressive effect of both CY and TBI on the immune functions (32-34) mediated by lymphocyte cytoreduction led to the idea that elimination of immunocompetent lymphocytes with anti-self-reactivity by irradiation or high dose $\mathrm{CY}$ may serve as a therapeutic approach to autoimmune diseases. CY has already been proven a very effective agent in inhibition of EAE (16-22); in contrast, results of experiments designed to investigate the effect of TBI on EAE have been controversial. Paterson et al. (35-37) claimed that TBI before immunization suppresses the development of EAE in rats, whereas irradiation after sensitization does not suppress $E A E$ and may even potentiate its development. On the other hand, other investigators (38-41) have reported that after TBI the clinical course of EAE is characterized by a delayed onset, reduced incidence, less severe paralysis, and a more rapid recovery. Sublethal doses of irradiation increase the incidence and severity of adoptively transferred EAE $(10,36,37)$; therefore this procedure has been used as a pretreatment of recipient mice before injection of LNC, to accelerate the development of the disease (EAE) (10, $36,37)$. The consistent, beneficial effect of TBI shown in our study may be attributed to the use of high, lymphocytotoxic doses (at the lethal range) of radiation and perhaps to the timing (day +5 or later) of administration.

The beneficial effect of both high dose TBI and CY on the course of CR-EAE that was clearly demonstrated in our study is in agreement with the general concept of immunosuppressive approaches for treatment of EAE; the doses of CY and TBI used induced a radical immunosuppression, with lymphocyte number close to zero during the first days after therapy.

Reconstituting lymphocytes developing from the early bone marrow progenitor cells after cytoreduction and rescue with SBMT acquire immunocompetence de novo to the "modified self" antigens, similar to the mechanism of unresponsiveness to "self" that occurs during the ontogeny of the immune system; this process may prevent generation of anti-self-reacting cells that may induce autoimmune disease.

Effective elimination or neutralization of the autoreactive lymphocytes, after the clinical onset of chronic paralytic disease in mice with CR-EAE, was always a difficult task, since it required continuous immunosuppressive treatment (22) or repetitive administration of specific antibodies against $\mathrm{T}$ lymphocytes and their L3T4 (T helpers) subset (26). Interestingly, a more aggressive immunosuppression followed by SBMT, applied at an early stage of the disease after the onset of the first signs of CR-EAE, can either totally inhibit or reverse the development of the disease.

We have also shown that only a few spontaneous relapses occurred in treated mice. When untreated mice with CR-EAE were challenged with GMBP in CFA $72 \mathrm{~d}$ after the injection of the MBP-sensitized lymphocytes, they developed a severe relapse (Table I $B$ ), while only three of the seven mice treated with TBI+SBMT and similarly rechallenged with GMBP displayed paralytic signs; in addition, this paralytic relapse in the TBI+SBMT-treated mice occurred after a delay of $>30 \mathrm{~d}$ after the GMBP inoculation (Fig. 3, Table I $B$ ). Our data are compatible with either one of the following interpretations: (a) development of partial anergy/tolerance to GMBP, as may be supported by the specific reduction of the in vitro proliferative responses of lymphocytes to GMBP and PPD (Table II); and/ or $(b)$ the existence of an antiidiotypic network similar to that reported in other studies, after injection of irradiated GMBPspecific lymphocytes (42). The delayed relapse in the 



Figure 6. Histopathological manifestations of CR-EAE in TBI+SBMT-treated mice and in untreated controls. $(A)$ Typical perivascular lymphocytic infiltrations into the periventricular white matter, in untreated mice and large areas of demyelination around the infiltrations (Luxol fast blue staining). (B) Absence of infiltrating lesions in a similar section of mice treated with TBI and SBMT (staining with hematoxylin/eosin). (C) Small lymphocytic infiltration into the cerebellar subcortical white matter of mice treated with TBI and SBMT (hematoxylin/eosin). 
TBI+SBMT-treated group resembles the model of actively GMBP-induced, delayed CR-EAE in SJL/J mice $(2,5)$ and can be attributed in our case to sensitization against another epitope of GMBP, different from the epitope that induced the primary activation of the lymphocytes and the first paralytic attack of CR-EAE.

We have previously shown that in actively induced acute EAE (30), treatment with CY or TBI and SBMT induces antigen-specific tolerance; however, in this model of CR-EAE, the tolerizing effect of this therapeutic regimen was somewhat less effective, probably due to lack of continuous antigenic/tolerogenic stimulation (there is no antigen/adjuvant emulsion in the body of treated mice as is the case in the actively induced form of EAE) during the process of immunological reconstitution. Antigens existing in the thymic environment during the process of immune reconstitution following BMT may induce deletion or anergy of specific $T$ cell clones bearing $T$ cell receptors specific for the relevant antigens (recognized as self-antigens) (43-46) by a mechanism resembling the ontogeny of the immune system during normal development. Moreover, persistence of the tolerizing auto- or allo-antigens is mandatory for maintenance of the unresponsive state (47). A similar beneficial therapeutic effect after TBI and BMT has been recently reported in the model of adjuvant induced autoimmune arthritis (48).

The limited success of treatment with TBI+SBMT in advanced CR-EAE (Fig. 5) could be attributed to the development of irreversible CNS lesions (gliosis) in addition to demyelination at such late stages of the disease (4).

Overall, results presented here show that this combined treatment of high dose acute immunosuppression followed by syngeneic BMT, which represents the experimental equivalent of autologous BMT, not only reverses already established CREAE but also results in long-term beneficial effects by inhibiting or ameliorating the paralytic relapses. Based on our experimental model, possible application of similar therapeutic approaches should be considered for life-threatening human neurological and other systemic autoimmune diseases.

\section{Acknowledgments}

This work was supported by the Zeev Aram research grant in multiple sclerosis and the Fannie R. Steinpress Fund.

\section{References}

1. Brown, A. M., and D. E. McFarlin. 1981. Relapsing experimental allergic encephalomyelitis in SJL mouse. Lab. Invest. 45:278-284.

2. Lublin, F. D., P. H. Maurer, R. G. Berry, and D. Tippett. 1981. Delayed relapsing experimental allergic encephalomyelitis in mice. J. Immunol. 126:819822.

3. Mokhtarian, F., D. E. McFarlin, and C. S. Raine. 1984. Adoptive transfer of MBP sensitized cells produced chronic relapsing demyelinating disease in mice. Nature (Lond.). 309:356-358.

4. Brown, A. M., D. E. McFarlin, and C. Raine. 1982. Chronologic neuropathology of relapsing experimental allergic encephalomyelitis in the mouse. $L a b$. Invest. 46:171-185.

5. Fritz, R., J. Chou, and D. McFarlin. Relapsing murine EAE induced by myelin basic protein. 1983. J. Immunol. 130:1024-1026.

6. Raine, C. 1984. Biology of disease. Analysis of autoimmune demyelination: Its impact upon multiple sclerosis. Lab. Invest. 50:608-635.

7. Bernard, C. C. A., J. Leydon, and I. R. Mackay. 1976. T cell necessity in the pathogenesis of experimental autoimmune encephalomyelitis in mice. Eur. $J$ Immunol. 6:655-660.

8. Pettinelli, C. B., and D. E. McFarlin. 1981. Adoptive transfer of experimental allergic encephalomyelitis in SJL/J mice after in vitro activation of lymph node cells by myelin basic protein: requirement for Lyt $1+2-T$ lymphocytes. $J$. Immunol. 127:1420-1423.
9. Sriram, S., D. Solomon, R. V. Rouse, and L. Steinman. 1982. Identification of $T$ cell subsets and $B$ lymphocytes in mouse brain experimental allergic encephalomyelitis lesion. J. Immunol. 129:1649-1651.

10. Ben-Nun, A., and Z. Lando. 1983. Detection of autoimmune cells proliferating to myelin basic protein and selection of $\mathrm{T}$-cell lines that mediate experimental allergic encephalomyelitis (EAE) in mice. J. Immunol. 130:1205-1209.

11. Field, E. J., and H. Miller. 1962. Experimental allergic encephalomyelitis: comparison of protective effects of prednisolone and corticotropin. Br. Med. J. 5281:843-844.

12. Kiebler, R. F. 1965. Large dose corticosteroid therapy of experimental and human demyelinating diseases. Ann. N. Y. Acad. Sci. 122:469-478.

13. Greig, M. E., A. J. Gibbons, and G. A. Elliot. 1970. A comparison of the effects of melengesterol acetate and hydrocortisone acetate on EAE in rats. $J$. Pharmacol. Exp. Ther. 173:85-93.

14. Komarek, A., and F. M. Dietrich. 1971. Chemical prevention of experimental allergic encephalomyelitis in rats: A quantitive evaluation of steroids and various non steroid drugs. Arch. Int. Pharmacodyn. Ther. 193:249-257.

15. Steiner, I., T. Brenner, R. Mizrachi-Kol, and O. Abramsky. 1991. Development of experimental autoimmune encephalomyelitis during steroid administration. Isr. J. Med. Sci. 27:365-368.

16. Paterson, P. Y., E. W. Gerner, F. M. Steele, and M. A. Hanson. 1966. Cyclophosphamide inhibition of an autoimmune disease, allergic encephalomyelitis. J. Clin. Invest. 45:1055. (Abstr.)

17. Paterson, P. Y., M. A. Hanson, and E. W. Gerner. 1967. Cyclophosphamide inhibition of experimental allergic encephalomyelitis in Wistar rats. Proc. Soc. Exp. Biol. Med. 124:928-932.

18. Paterson, P. Y., and G. D. Drobish. 1969. Cyclophosphamide: effect on experimental allergic encephalomyelitis in Lewis rats. Science (Wash. D.C.). 165:191-192.

19. Rosenthale, M. E., L. J. Datko, J. Kassarich, and F. Shneider. 1969 Chemotherapy of experimental allergic encephalomyelitis (EAE). Arch. Int. Pharmacodyn. Ther. 179:251-275.

20. Levine, S., and R. Sowinski. 1977. Suppression of the hyperacute form of EAE by drugs. Arch. Int. Pharmacodyn. Ther. 230:309-318.

21. Staykova, M., I. Goranov, and T. Nikolov. 1978. L'influence du cyclophosphamide sur le development de EAE. Ann. Immunol. (Paris). 129:415-427.

22. Lublin, F. D. 1984. Immunomodulation of relapsing experimental autoimmune encephalomyelitis. Neurology. 34:1615-1617.

23. Feurer, C., C. H. Chow, and F. Borel. 1988. Preventive and therapeutic effects of cyclosporin and valine-dihydro cyclosporin in chronic relapsing EAE in Lewis rats. Immunology. 63:219-223.

24. Schuller-Levis, G. B., P. B. Kozlowski, and H. M. Wisniewski. 1986. Cyclosporin A treatment of an induced attack in a chronic relapsing model of experimental allergic encephalomyelitis. Clin. Immunol. Immunopathol. 40:244-252.

25. Strober, S., B. Kotzin, E. Field, R. Hoppe, B. Myers, A. Tanay. 1986 Treatment of autoimmune disease with TLI: cellular humoral mechanisms. Ann. N. Y. Acad. Sci. 475:285-295.

26. Waldor, M. K., R. Sriram, L. A. Hardy, L. Herzenberg, M. Lanier, M Lim, and L. Steinman. 1985. Reversal of EAE with monoclonal antibody to a T cell subset marker. Science (Wash. D.C.). 227:415-417.

27. Brostoff, S. W., and D. W. Mason. 1984. Experimental allergic encephalomyelitis: successful treatment in vivo with a monoclonal antibody that recognized T-helper cells. J. Immunol. 133:1938-1942.

28. Sriram, S., and C. A. Roberts. 1986. Treatment of established chronic-relapsing experimental allergic encephalomyelitis with anti-L3T4 antibodies. $J$. Immunol. 136:4464-4469.

29. Brod, S. A., A. Al-Sabbagh, R. A. Sobel, D. A. Hafler, and H. L. Weiner. 1991. Suppression of experimental autoimmune encephalomyelitis by oral administration of myelin antigens: IV. Suppression of chronic relapsing disease in the Lewis rat and strain 13 guinea pig. Ann. Neurol. 29:615-622.

30. Diebler, G. E., R. E. Martenson, and M. W. Kies. 1972. Large scale preparation of MBP from central nervous tissue of several mammalian species. Prep. Biochem. 2:139-165.

31. Karussis, D. M., D. Lehmann, S. Slavin, A. Ben-Nun, and O. Abramsky. 1991. Immunosuppression by high-dose cytoreductive therapy and bone marrow transplantation (BMT), as a therapeutic approach in chronic-relapsing experimental autoimmune encephalomyelitis. Neurology. 41:361. (Abstr.)

32. Tochner, Z., and S. Slavin. 1988. Immune modulation by ionized irradiation. Curr. Opin. Immunol. 1:261-268.

33. Anderson, R. E., G. Olson, J. Autry, J. Howarth, G. Troup, and P. Bartels. 1977. Radiosensitivity of T and B lymphocytes: effect of whole body irradiation upon various lymphoid tissues and numbers of recirculating lymphocytes. $J$. Immunol. 118:1191-1200.

34. Stockman, G. D., L. R. Heim, M. A. South, and J. J. Trentin. 1973 Differential effects of cyclophosphamide on the B and $\mathrm{T}$ cell compartments of adult mice. J. Immunol. 110:277-282.

35. Paterson, P. Y., and N. E. Beisaw. 1963. Effect of whole body X-irradiation on induction of allergic encephalomyelitis in rats. J. Immunol. 90:532-539.

36. Paterson, P. Y., W. P. Richardson, and D. G. Drobish. 1975. Cellular 
transfer of experimental allergic encephalomyelitis: altered disease pattern in irradiated recipients Lewis rats. Cell. Immunol. 16:48-59.

37. Paterson, P. Y., and J. Harvey. 1978. Irradiation potentiation of cellular transfer of experimental allergic encephalomyelitis: time course and locus of effect in irradiated recipient Lewis rats. Cell. Immunol. 41:256-263.

38. Oldendorf, W. H., and E. M. Conford. 1977. A comparison of total body and local spinal cord irradiation in experimental allergic encephalomyelitis. $J$. Neuropathol. \& Exp. Neurol. 36:50-61.

39. Candie, R. M., and T. Nicholas. 1962. Effect of total body irradiation on the development of experimental allergic encephalomyelitis. Fed. Proc. 21:43. (Abstr.)

40. Visakorpi, R., and T. U. Kosunen. 1972. The effect of whole body X-irradiation on experimental allergic encephalomyelitis in the rat. Ann. Med. Exp. Biol. Fenn. 50:95-97.

41. Vitale, B., N. Allegretti, and M. Matosic. 1966. Influence of X-irradiation on experimental allergic encephalomyelitis in rats. Radiat. Res. 28:727-734.

42. Lider, O., T. Reshef, E. Beraud, A. Ben-Nun, and I. Cohen. 1988. Antiidiotypic network induced by $\mathrm{T}$ cell vaccination against experimental autoimmune encephalomyelitis. Science (Wash. D.C.). 239:181-183.
43. Speiser, D. E., Y. Chvatchko, R. M. Zinkernagel, and H. R. MacDonald. 1990. Distinct fates of self-specific $T$ cells developing in irradiation bone marrow chimeras: clonal deletion, clonal anergy, or in vitro responsiveness to self-Mls-1 controlled by hemopoietic cells in the thymus. J. Exp. Med. 172:1305-1314.

44. Matsuzaki, G., Y. Yoshikai, M. Ogimoto, K. Kishiihara, and K. Nomoto. 1990. Clonal deletion of self-reactive $T$ cells at the early stage of $T$ cell development in thymus of radiation bone marrow chimeras. J. Immunol. 145:46-51.

45. Eto, M., H. Mayumi, Y. Tomita, Y. Yoshikai, Y. Hishimura, T. Maeda, T. Ando, and K. Nomoto. 1991. Specific destruction of host-reactive mature T cells of donor origin prevents graft-versus-host disease in cyclophosphamide induced tolerance. J. Immunol. 146:1402-1409.

46. Eto, M., H. Mayumi, Y. Tomita, Y. Yoshikai, and K. Nomoto. 1990. Intrathymic clonal deletion of $\mathrm{V}_{\mathrm{bb}} \mathrm{T}$ cells in cyclophosphamide-induced tolerance to H-2-compatible, MIs-disparate antigens. J. Exp. Med. 171:97-113.

47. Morecki, S., B. Leshem, A. Eid, and S. Slavin. 1987. Alloantigen persistence in induction of transplantation tolerance. J. Exp. Med. 165:1468-1480.

48. Van Bekkum, D. W., E. P. M. Bohre, P. F. J. Houben, and S. KnaanShanzer. 1989. Regression of adjuvant-induced arthritis in rats following bone marrow transplantation. Proc. Natl. Acad. Sci. USA. 86:10090-10094. 